resistance in the abdominal wall would interfere with the descent of the bladder.

In the view (3) the assumption of a temporary obstruction to the flow of urine is extremely hypothetical and there are difficulties in the way. Although all the cases published have been of the male sex there is no evidence of any urethral obstruction; phimosis has been noted in some of the cases but only to a very slight degree. If the wasting of the abdominal muscles be due to stretching over a dis. tended bladder it is difficult to see why only the lower segments should be affected while the tension must be equally distributed from ensiform to pubes. Moreover, in cases of ascites of extreme degree we do not meet with wasting in the stretched muscles. Again, if the change in the muscles be due to a pressure atrophy one would expect to find more definite results in the way of local reaction to the pressure, whereas no such are found; it is possible, of course, that the condition is so far advanced that these early changes have disappeared.

The ureteral and kidney changes need not be further discussed as they are quite clearly secondary results to the changes elsewhere.

$A$ further consideration of the view (2) leads to the idea that it may be possible for both muscle and bladder changes to be due to a common cause of developmental origin, and that perhaps as the result of some vascular cause there arose a failure of a portion of the segmental development associated with a defect in the nature of an excess in the neighbourhood of the trigone of the bladder in that portion which arises from the hypoblast of the cloaca. Such a hypertrophy (which may have an analogue in the hypertrophy about the pylorus) might be associated with a relative stenosis of the ureteral orifices and a consequent dilatation in these ducts and in the pelves of the kidneys with still later secondary changes in those organs. Still, if this hypertrophy did occur we might reasonably expect it to occur alone without the constant accompaniment of deficiency in the abdominal walls

On the whole the hypothesis of a defective development in the abdominal muscles which thus render no assistance to the descent of the bladder and allow an abnormal direction to the ureters at their entrance into the bladder, seems to be the most likely and to bring into line the condition of the genito-urinary organs with what appears to be fairly clearly a developmental anomaly of the abdominal muscles.

Newcastle-on-Tyne.

\section{A CASE OF "CAISSON DISEASE."}

BY F. H. RUDGE, M.R.C.S. ENG., L.R C.P. LOND., LATE HOUSE SURGEON TO THE TORBAY HOSPITAL, TORQUAY.

CaIsson disease is a condition so rarely seen that no apology is necessary for publishing in detail the notes of a case. It would perhaps be not out of place if in a few preliminary remarks reference were made to the causes of the disease and the means taken to prevent it.

The term "caisson disease" is applied to a series of phenomena to which workers in caissons and divers in deep water are liable-in fact, all workers in compressed air in whatever circumstances expose themselves to the risk of this malady. A caisson is a cylinder of steel sunk in water, the water being excluded by means of compressed air. A diver in a diving-dress like the "caissonier" is working in compressed air, the condition of each, when working, being therefore almost identical. The caissonier, however, does not work at such a high atmospheric pressure bat the exposure to pressure is of longer duration. The causes of the disease are first, too long exposure to pressure and, secondly, too rapid decompression. These two canses may be combined. By decompression is meant the gradual reduction of any pressure over and above that of one atmosphere. Certain means to prevent the occurrence of these causes bave been adopted and the data that are now worked upon have been arrived at by exhaustive experiments on animals and by observations made during diving operations. The result of these experiments and observations has been such that the incidence of symptoms is comparatively rare and the diver can now work at greater depths and with more assured safety than heretofore. The duration of decompression should bear a definite ratio to the duration of exposure to pressure and to the amount of pressure. The most constant morbid phenomenon which has been observed at necropsies on men and animals is the presence of "bubbles" to a varying extent in the blood-vessels, heart, joints, and loose tissues. These bubbles have been demonstrated to consist of pure nitrogen. Their presence requires explanation. When a gas is in contact with a liquid under pressure the tendency is for the liquid to receive the gas in simple solution. Inspired air is practically in contact with the blood in the lungs and therefore when a diver is exposed to pressure the blood takes up an increased proportion of oxygen and nitrogen. So long as this pressure is maintained no harm accrues, neither does it if the pressure is gradually diminished. Should, however, the pressure be rapidly removed, or, in other words, should decompression be too rapid, the blood which was previously saturated tends to become hypersaturated. This tendency is overcome by the gases being set free in the form of bubbles - the carbon dioxide being eliminated by the lungs while the nitrogen finds its way into the circulatory system and loose tissues. To make this point clearer one may take as a simile a bottle of soda-water. Soda-water, as is well known, consists of water into which carbon dioxide has been forced under pressure. So long as the cork remains in the bottle no bubbling occurs, but as soon as it is removed, or, in other words, so soon as the pressure inside the bottle approaches to that of the atmosphere, bubbles are given off in abundance. This is what happens to a too rapidly decompressed diver or caissonier, the extent of the bubbling depending on the amount of pressure, the duration of pressure, and the rapidity of decompression. The reason these bubbles are composed of nitrogen only and do not contain any oxygen or carbon dioxide is explained by the fact that whereas oxygen enters into chemical combination with the tissues or is eliminated in the expired air as carbon dioxide, nitrogen does not combine with anything. With these few preliminary remarks I will proceed to describe the case in detail.

The patient, a man, aged 49 years, was admitted to the Torbay Hospital under the care of Dr. J. H. Gough. He had been engaged as diver in the examining of torpedo-boat No. 99 which went down in 25 fathoms (150 feet) of water four and a half miles off Berry Head. He was an experienced diver and had made two previous descents on different days. The patient was admitted at 7.30 A.M. On the previous night he left the surface to go down to the wreck at 7.12 o'clock and owing to the fact that his lines were fouled by the wreckage he was not brought to the surface until 12.15 A.M. When it was found possible to raise him he was brought up to within 50 feet of the surface and then decompressed as indicated in the following table :-

Depth in feet.

Stoppages in minutes.

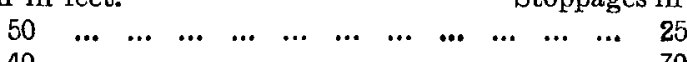

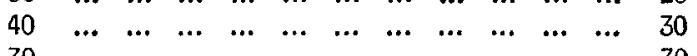

$$
\begin{aligned}
& \begin{array}{llllllllllllll}
30 & \ldots & \ldots & \ldots & \ldots & \ldots & \ldots & \ldots & \ldots & \ldots & \ldots & \ldots & 30
\end{array} \\
& \begin{array}{lllllllllllll}
20 & \ldots & \ldots & \ldots & \ldots & \ldots & \ldots & \ldots & \ldots & \ldots & \ldots & \ldots & 30 \\
10 & \ldots & \ldots & \ldots & \ldots & \ldots & \ldots & \ldots & \ldots & \ldots & \ldots & \ldots & 45
\end{array}
\end{aligned}
$$

On coming to the surface he was so exhausted as to be unable to get on board without assistance. When his face-piece was removed he was able to answer questions and apart from the exhaustion did not appear to be much the worse for his immersion. He was covered with blankets and given hypodermic injections of ether and brandy. There were no signs of dyspncea and his radial pulses were good. One $\mathbf{h}$ רur later he complained of "bends" in the right arm and knees. These "bends" are a fairly constant sign of this malady and consist of bending of the limbs accompanied by pain. His hearing was unimpaired. The pains and "bends" passed off and he slept. On arrival at the hospital his condition was as follows. His colour was good but the expression was rather anxious. There was no lividity of the face or of any part of his body. He was able to take an intelligent interest in his surroundings and to make his wants known but he was quite deaf. Inspiration was deep and prolonged, expiration being short and shallow. His bands were very cold and the surface temperature generally appeared to be below normal. The temperature taken in the axilla was $97 \cdot 6^{\circ} \mathrm{F}$., the pulse was 114 (carotid), and the respirations were 32 . With regard to the circulatory system no cardiac impulse could be seen or felt. There was slight dilatation of the right side of the heart. The heart sounds could only occasionally be heard and were then very muffled. No bruits were heard. Neither radial pulse could be felt nor was any pulsation palpable over the femoral, popliteal, tibial, or dorsalis pedis arteries. Pulsation was 
easily felt in the carotids. There were no subcutaneous bæmorrbages and no epistaxis. As to the respiratory system, there was no dyspncea. The chest moved well and equally on respiration and on auscultation no adventitious sounds were heard. The air entry was good all over the back and the front. There was no cough. With regard to the alimentary system, the tongue was clean and there was no vomiting. The bowels were opened slightly once but there was nothing abnormal in the stools. The patient suffered from great thirst and frequently asked for a drink. There was no dysphagia. As to the urinary system, urine was passed (about 12 ounces) one hour after admission; it was acid and contained no albumin or sugar. The specific gravity was 1025 . As to the nervous system, there was no paralysis. The knee jerks were not easily obtained but were present. Sensation in the legs and trunk was unimpaired. "Bends" were absent. He did not resent a deep needle-prick made in his thumb and ear for the purpose of obtaining blood fcr examination. There were no pupillary changes. Examination of the abdomen revealed nothing abnormal. No particular inference can be drawn from the result of the examination of the blood as the circulation was so sluggish that considerable pressure had to be used before sufficient could be obtained. The result obtained was as follows: hæmoglobin, 102 per cent. ; erythrocytes, 7,317,000 ; leucocytes, 8000 ; polymorphonuclears, $75 \cdot 73$ per cent.; large mononuclears, 6.54 per cent.; small mononuclears $15 \cdot 73$ per cent.; and eosinophiles, $2 \cdot 0$ per cent. The blood was very dark in colour.

Observations made up to the time of death.-His condition during the morning did not show any marked change. He made his wants known in a coherent manner and could understand questions written on a slate. In the early afternoon he complained of his ears and asked if nothing could be done to relieve his deafness. He also complained of some abdominal pain. He was rather restless and frequently shifted from one side to the other in an impatient manner. He continuously manifested anxiety as to his condition by saying, "Am I all right?" At about 7 30 P M. his restlessness increased and he became incoherent. Lividity of the face was noticed but it varied in intensity and was more marked during the periods of restlessness, disappearing almost entirely during the quiescent intervals. Later the restlessness became of such a violent nature as to necessitate forcible restraint. $\mathrm{He}$ did not recognise his wife who visited him at about 8.30 P.M. His rectal temperature at this time was $102 \cdot 4^{\circ}$. No further change was noticed until 11.30 P.M., when he appeared to become suddenly worse. His respirations were shallow, stertorous, and jerky, and he was comatose. His corneal reflexes were absent and his face was pallid. Oxygen was administered and artificial respiration performed but he died a few minutes after midnight. The radial pulses, though frequently looked for, were never felt nor could the heart sounds be heard at all during the latter part of the day. There were never any signs in the lungs, both bases being quite clear when examined shortly before death. During the last few hours there was profuse general perspiration. The legs and trunk were fairly warm, but the hands were from the time of admission very cold and later became cyanosed. It is possible that this may be accounted for by the fact that the sleeves of the diving dress fit very tightly round the wrists. That the circulation was very sluggish was demonstrated by the fact that repeated and deep punctures with a large Hagedorn needle caused no escape of blood without considerable pressure.

Treatment.-On admission he was given five minims of strychnine subcutaneously. This was repeated in threeminim doses two hourly for ten hours. Milk and brandy were administered by the mouth at frequent intervals. When the lividity appeared oxygen was given at short intervals, which minimised the lividity and decreased the restlessness, but the good effect was very transitory. A quarter of a grain of morphine was given in order to overcome the restlessness, if possible, and five grains of phenacetin combined with three of caffeine citrate to act as an antipyretic. Whether these drugs had the desired effect was never known, as he died shortly after their administration.

Necropsy (performed 15 hours after deat $h$ ).-Rigor mortis was well marked. There was well-marked post-mortem lividity at the dependent parts of the trunk, especially at the back and sides of the head, including the ears. The abdomen was very distended. (This was post mortem as no distension was present ten minutes before death.)
There were no subcutaneous hæmorrbages. On making the usual incision the subcutaneous fat which was excessive was reddish and mottled in appearance, looking like fresh bonemarrow. It was also very greasy. On opening the peritoneum a light yellow oily fluid escaped which on investigation was found to have origin in the omental fat. The omental fat had the same characteristics as noted above with reference to the subcutaneous fat. The omentum was friable and had in places become closely adherent to the parietal peritoneum. The mesenteric vessels were obliterated by excess of fat. The intestines and stomach were distended with gas and the surface of the former was mottled. Numerous bubbles were found in the omental fat and in the veins on the surface of the stomach. Blood flowed freely from cut vessels and was dark in colour. Examination of the heart showed that there was a normal amount of fluid in the pericardium. The right ventricle was slightly dilated but not distended. There was excess of fat in the heart walls but apparently no fatty degeneration. Bubbles were well marked in the coronary veins. On dividing the innominate artery bubbles escaped. The right ventricle contained a large amount of dark, almost black, clot in which a number of bubbles were seen. The right auricle was full of clot but there were no bubbles. No bubbles excaped on division of the inferior vena cava, All the valves were quite healthy but there was slight atheroma of the aorta. The lungs wore quite normal. No bubbles were seen in the azygos veins. A few were observed in the veins on the surface of the diaphragm. The liver was not enlarged and was normal in appearance. On section and pressure bubbles escaped from the cut surface. Four medium-sized stones were found in the gall-bladder. The spleen showed nothing abnormal except that it was rather pale. The kidneys on section and pressure produced a few bubbles. The left renal vein contained a large bubble. With regard to the brain, on incising the scalp a large amount of dark blood escaped. The meninges and the brain substance were quite normal. No bubbles were found anywhere. The choroid plexuses and ventricles were normal. The spinal cord was not examined. No bubbles were found in any of the peripheral arteries. The right knee-joint was opened and a number of bubbles escaped with the synovial fluid.

Remarks.-The course which this case ran is unusual in that death was evidently caused by the gradual formation of bubbles combined with extreme exhanstion consequent on the patient's prolonged immersion. That babbles should have formed at all indicates that the period of decompression, although so long, was not long enough. To have increased the duration of decompression would have been to expose the man to the very grave risk of death from exhaustion before he reached the surface. Had the presence of bubbles been manifested earlier recompression might have been resorted to, perhaps with success. As, however, he showed no serious signs of insufficient decompression until be was in the hospital it would have been an obviousky ill-judged proceed. ing to bave transferred him to the recompression chamber in the condition he was then in.

Such complete saturation at such great pressure as this man experienced is, I believe, unique.

I wish to take this opportunity of recording my indebted. ness to Dr. Gough for permission to publish this case and also to Professor J. S. Haldane, Staff-surgeon O. Rees, R.N., and Lieutenant Damant, R.N., for much valuable assistance in the compilation of the same. Clifton.

\section{THREE SUCCESSFUL CASES OF OPERA. TION ON THE LABYRINTH. ${ }^{1}$}

BY SYDNEY R. SCOTT, M.S. LOND., F.R.C.S. ENG., CHIEF ASSISTANT, AURAL DLPARTMENT, ST. BARTHOLOMEW'S HOSPITAI, AND AURAI SURGEON, EVELINA HOSPITAI FOR SICK CHILDREN.

IN these three cases the labyrinthine disease arose as a complication of chronic suppurative otitis media. Two cases 1 operated upon in the aural department at St. Bartholomew's Hospital this year (1907). They occurred in the practice of Mr. A. E. Cumberbatch and Mr. C. F. West, through whose kindness I was afforded opportunities of making the following observations. The third case, which I operated upon

1 The first two cases were shown at the inaugural meeting of the The first two cases were shown at the inaugural meeting of the
Otoligical Section of the Royal Society of Medicine, Dec. 7 th, 1907 . 